ARTICLE

Received 30 Sep 2016 | Accepted 10 Apr 2017 | Published 9 May 2017

\title{
The challenge of transformative experiences for advance directives: predicting a future with Alzheimer's disease
}

Kyle Boerstler ${ }^{1}$

\begin{abstract}
Some of the experiences that are possible in life are not relatable to others, nor can one learn about them in other ways, at least not in the sense of what it is like to have lived the experience. L.A. Paul calls these kinds of experiences transformative experiences. This article will incorporate Paul's concept into an argument that undermines the moral authority of advance directives in situations where the instructions stated in the directive are in direct conflict with the contemporary interests of a patient who suffers from Alzheimer's disease. Though the conclusion of this paper will be similar to many others in the literature, namely that advance directives should not in all cases be the final authority on how to respect a patient's autonomy, this article will argue for this kind of a thesis in a unique way because it will emphasize the importance of that which no one can know. The argument contends that the lived experience of Alzheimer's disease is a transformative experience, such that one cannot weigh the subjective value of what it is like to be a person with Alzheimer's disease in the relevant way to properly assess the possible future interests and preferences when creating an advance directive. This article is published as part of a collection on selfknowledge in and outside of illness.
\end{abstract}

\footnotetext{
${ }^{1}$ Florida State University, Tallahassee, FL, USA Correspondence: (e-mail: krb14d@my.fsu.edu)
} 


\section{Introduction}

ometimes, in the face of the complexities of life, we rely on hypotheticals to aid us in decisions concerning the future. This is no less the case when a patient is deciding about their future care in crafting an advance directive. I take an advance directive to be a document that is created by a patient to ensure that certain interests or preferences are protected in the event that they are unable to exercise their own autonomy in medical decision making, and the specificity of such documents ranges from the very vague to the very precise. In particular, I am interested in discussing the case of a patient who creates a directive in the face of the onset of Alzheimer's disease, and whether or not the authority of the advance directive ought to be binding in such a case (or similar ones). I argue that it should not be binding due to the fact that the very act of using hypotheticals to predict our preferences is difficult under normal circumstances, but when presented with an experience like Alzheimer's disease it becomes impossible, namely because the case of Alzheimer's disease can be classified as a transformative experience.

In section two of the article, I will briefly review the literature on advance directives to situate the debate. In section three, I present the concept of a transformative experience and explain how I will use this concept for my argument. In section four, I will present and examine a hypothetical case of Alzheimer's disease where the patient suffers from severe dementia, arguing that an advance directive in such a case cannot be binding. In the final section, I will draw some preliminary conclusions from my argument, and explain why advance directives may still have use despite the undermining of their moral authority.

\section{Situating the debate}

Some may believe that a paper of this nature is akin to beating a dead horse, as the conflict generated by advance directives has already been heavily discussed in the literature. In an effort to sway that opinion, I will attempt to lay out the current status of the debate surrounding my own argument and explain how my argument will help to advance at least one aspect of the conflict. Over three decades ago, Dresser (1986) claimed that "courts and legislatures have strayed from their declared mission", namely to attempt to show deep concern for incompetent patients and protect their interests. She argues that while law-makers believed that the best way to accomplish their mission was to treat incompetent patients as competent ones, in reality this approach ignored the genuine interests of the incompetent patients. Most notably, Dresser also argues that the patient who creates an advance directive and later becomes incompetent will not be able to reconcile any changes in their own conception of the good that have occurred since the creation of the document. ${ }^{1}$ Ronald Dworkin later argued that in fact respecting the formerly competent patient's wishes is the best way to respect autonomy, since the competent patient will have expressed their "critical interests" in such wishes. A critical interest is an interest that concerns the patient's long-term goals and projects, which are reflected in how a life can end well or badly (Dworkin, 1993). Dresser rejoins the argument and counters Dworkin, claiming that in the case of incompetent patients, it is rather the "experiential interests" that ought to be protected, since the demented patient has no appreciation of former critical interests. Others have criticized Dworkin's argument, but many have also taken up his line of thinking and expanded upon it. John K. Davis and David Degrazia supply arguments in support of what Davis calls "the extension view," which appeal to favoring the directive as the best way to promote and protect autonomy (Davis, 2009). Helpfully, Agnieszka Jaworska has more recently organized the prevailing issues of the advance directive debate into four categories: (1) Appeal to the forward-looking perspective of decision-making; (2) Exercise of will as the point of autonomy; (3) Loss of personal identity; (4) Severance of prudential concern (Jaworska, 2009). I am most interested in the set of arguments contained in the first challenge. This sets at least a few of the primary issues at play in the debate on the table, and I will reference more arguments as they become relevant to my own argument in the coming sections. ${ }^{2}$ I believe my argument will advance the debate by providing a fresh argument to supplement the problem of forward looking decision-making while also being able to accept key arguments that those in favor of honoring the advance directive make. In this way, I hope to provide at least one path forward for those who find themselves persuaded by different arguments on both sides of the debate.

\section{Transformative experiences}

Two definitions are vital to understanding Laurie Paul's concept of a transformative experience:

Epistemically Transformative (ET): An experience that teaches you something you could not have learned without having that kind of experience. The experience teaches you what that kind of experience is like, and gives us new abilities to imagine, recognize, and cognitively model possible states.

Personally Transformative (PT): An experience that changes you in some deep and personally fundamental way, for example, by changing your core personal preferences or by changing the way you understand your desires, defining intrinsic properties, or perspective. ${ }^{3}$

An ET experience is one that alters our cognitive abilities in a fundamental way. As I emphasize in the definition above, the experience teaches you something you cannot learn prior to having the experience. To explain this, Paul offers by analogy her version of an example from Frank Jackson about Mary, an ordinary girl who has been confined to a black-and-white room since birth. As Paul says, "When Mary finally decides to leave her room, she sees color for the first time ... When Mary sees red, she has a dramatically new experience: she now knows what it is like to see red, and more generally, she now knows what it is like to see color" (Paul, 2015a). Even with all the knowledge that science could provide Mary concerning the color red, she could not have known what the experience would be like. Having only experienced the colors black and white in her limited world, seeing red changed her cognitive abilities. Post-experience Mary can now recall what it is like to see red, and can imagine what it will be like to see red again. ${ }^{4}$

An experience can be PT "[I]f an experience changes you enough to substantially change your point of view, thus substantially revising your core preferences or revising how you experience being yourself..." (Paul, 2014). These kinds of experiences can include things like getting married, having a child, going to war, or having a religious conversion. ${ }^{5}$ Because experiences like these will "substantially revise your core preferences," it is difficult (if at all possible) to know much of anything about the person you will become, since you cannot grasp how your preferences will shift and how your perception of the world will change. ${ }^{6}$ Now that I have explained what an ET and a PT experience are, I can introduce transformative experiences. They are defined below:

Transformative Experience (TE): An experience that is both epistemically and personally transformative. 
In her book, Paul offers the analogy of choosing whether or not to become a vampire as a paradigm case of a TE. ${ }^{7}$ For example, in deciding whether to become a vampire, one cannot learn what it is like to be a vampire before actually becoming one. Thus, any projections (of the relevant sort for decision theory) about being a vampire are impossible, making this experience ET. ${ }^{8}$ Further, once one becomes a vampire, one's core preferences will drastically shift (averse to sunlight, prefer blood to other foods, etc.), and so it is also a PT experience. Therefore, how can one rationally choose whether or not to become a vampire? ${ }^{9}$ It seems as if the relevant data are inaccessible, and so any decision made in this case should not rely on evidence gained from hypothetical projections into the future of what it is like to be a vampire. Yet, this is exactly what most people do when they are making important decisions, not the least of which includes crafting an advance directive.

This is where my argument finds traction in Paul's concept. I do not need to accept her strong conclusion, that in all transformative experiences involving high-stakes cases one cannot rationally decide what to do. Rather, because of the specific manner of creating an advance directive, a patient relies almost exclusively on hypothetical projections about their own interests to decide what ought to be done in various medical circumstances. In some low-stakes decisions, one can rely on testimonial knowledge to make a decision in which future outcomes are unknown. However, an advance directive clearly is a high-stakes decision (or at least has the potential to be such), and Paul argues that in these high-stakes decisions, testimonial knowledge is not enough to license a decision (Paul, 2015a). ${ }^{10}$ In non-TE's, Paul argues that hypothetical projections about future interests or outcomes can supplement testimonial knowledge. However, in the case of a TE, these supplemental sources are not available, and hence drive her argument to the conclusion that such decisions cannot be made rationally.

If I accept Paul's conclusion here, then I have to say that one cannot craft an advance directive in the face of a TE rationally. Another way to put it is that the patient cannot meet the requirements of informed consent or autonomy in such a case. ${ }^{11}$ However, if I do not accept Paul's strong conclusion, I can still accept a weaker version of her argument such that if a decision relies almost solely on hypothetical outcomes, it is not rational. ${ }^{12}$ There may still be a local problem specifically in the formation of an advance directive because the root of their authority stems from the patient's ability to be able to accurately predict their future preferences, and I will discuss why in the following sections. ${ }^{13}$ One may object here that the requirements of rationality may simply be too high if one cannot be rational about such a decision. For example, a patient may be able to accurately predict various aspects of their circumstances beyond the TE, and as such is capable or rationally choosing a course of action. However, I would respond that the point of Paul's concept is not that one cannot accurately predict certain circumstances, but rather that one cannot know from the inside, as it were, what it is like to experience life on the other side of the TE. Even if one still insists on the rationality objection, I argue that the binding nature of an advance directive is at least questionable in the case where a patient is limited in their epistemic capability to predict future preferences or interests. I will say more about this in the next section.

I want to say a bit more here about capability before moving on to the next section. When I use the term, I mean to say something akin to decision-making capacity which has several criteria that are assessed in a patient. They are: (1) ability to understand relevant information, (2) ability to appreciate the nature of the disorder and the possibility that treatment could be beneficial, (3) ability to reason about the treatment choices, and (4) ability to communicate a choice (Trachsel et al., 2015). When a patient is deciding about future treatment, I do not argue that (1), (3), or (4) are impossible to do (albeit some are more difficult than others). However, due to the nature of a TE, (2) is limited, and as such a decision in an advance directive will be challengeable on these grounds. The patient cannot appreciate the nature of a disorder like dementia (as in the case to come) without having first experienced it, but of course once the patient experiences moderate to severe dementia, competency is lost, and with it the ability to appreciate the disorder from the inside.

\section{Alzheimer's disease and transformative experiences}

Before giving the case, I will introduce the Reisberg Scale here for those unfamiliar with it. The Reisberg scale, also called the Global Deterioration Scale, is a diagnostic tool usable by both care-givers and physicians in measuring the progression of Alzheimer's Disease. I will reference the various stages in my case, which are given here:

- Stage 1-No impairment. Memory and cognitive abilities appear normal.

- Stage 2-Minimal Impairment/Normal Forgetfulness. Memory lapses and changes in thinking are rarely detected by friends, family, or medical personnel, especially as about half of all people over 65 begin noticing problems in concentration and word recall.

- Stage 3-Early Confusional/Mild Cognitive Impairment. While subtle difficulties begin to impact function, the person may consciously or subconsciously try to cover up his or her problems. Difficulty with retrieving words, planning, organization, misplacing objects, and forgetting recent learning, which can affect life at home and work. Depression and other changes in mood can also occur. Duration: 2-7 years.

- Stage 4-Late Confusional/Mild Alzheimer's. Problems handling finances result from mathematical challenges. Recent events and conversations are increasingly forgotten, although most people in this stage still know themselves and their family. Problems carrying out sequential tasks, including cooking, driving, ordering food at restaurants, and shopping. Often withdraw from social situations, become defensive, and deny problems. Accurate diagnosis of Alzheimer's disease is possible at this stage. Lasts roughly 2 years.

- Stage 5-Early Dementia/Moderate Alzheimer's disease. Decline is more severe and requires assistance. No longer able to manage independently or recall personal history details and contact information. Frequently disoriented regarding place and or time. People in this stage experience a severe decline in numerical abilities and judgment skills, which can leave them vulnerable to scams and at risk from safety issues. Basic daily living tasks like eating and dressing require increased supervision. Duration: an average of 1.5 years.

- Stage 6-Middle Dementia/Moderately Severe Alzheimer's disease. Total lack of awareness of present events and inability to accurately remember the past. People in this stage progressively lose the ability to take care of daily living activities like dressing, toileting, and eating but are still able to respond to nonverbal stimuli, and communicate pleasure and pain via behavior. Agitation and hallucinations often show up in the late afternoon or evening. Dramatic personality changes such as wandering or suspicion of family members are common. Many can't remember close family members, but know they are familiar. Lasts approximately 2.5 years.

- Stage 7-Late or Severe Dementia and Failure to Thrive. In this final stage, speech becomes severely limited, as well as the ability to walk or sit. Total support around the clock is needed for all functions of daily living and care. Duration is impacted by quality of care and average length is 1 to 2.5 years. ${ }^{14}$ 
Here is the case, a familiar one in the literature that I have adapted for my purposes: Mr Smart is an intellectual who develops an advance directive (in particular a living will). ${ }^{15}$ This directive stipulates that if he were ever cognitively impaired to the point that he could not read philosophy and comprehend it, then he would not want medical treatment in the case of a "lifethreatening" illness. ${ }^{16}$ As it happens, Mr Smart begins to suffer from symptoms that indicate the early stages of Alzheimer's disease shortly after developing this directive. If Mr Smart were to consult a physician about his symptoms, a physician would measure him at Stage 2 or Stage 3 on the Reisberg scale. Noticing that he is having problems with everyday tasks, Mr Smart still applies himself to his beloved philosophy. Though he cannot comprehend it as well as he used to, Mr Smart deceives himself (and boasts to others) that he is as sharp as ever. However, as he continues to decline, it becomes more obvious that he is becoming cognitively impaired. He is eventually diagnosed as having Alzheimer's disease, and is measured at Stage 4 on the Reisberg scale.

The disease progresses to stage 6 and Mr Smart can no longer readily recall who he is, who his family members are, and loses the ability to function as an independent person. He is given constant care in a facility and is described as "pleasantly demented." In other words, despite his diminishing cognitive capacities he seems to genuinely enjoy his daily routine at the facility. He is oblivious to the fact that he is no longer able to comprehend his (previously) precious philosophy books. While in this stage, Mr Smart develops Pneumonia, which will likely kill him without treatment. Based on his advance directive, treatment will be withheld since it stipulates that he should not receive "medical treatment in the case of a 'life-threatening' illness". Mrs Smart (and the doctors attending Mr Smart) is torn. On the one hand, she desires to obey the wishes of her husband as laid out in the directive. However, on the other hand she cannot help but think that in a lucid moment Mr Smart would desire to continue enjoying the seemingly pleasant life that he is currently living. ${ }^{17}$

I argue that $\mathrm{Mr}$ Smart's advance directive should not be considered binding in this case (legally or morally) since he has gone through a transformative experience via his disease. Alzheimer's disease impairs a person's cognition over time, and as such Mr Smart could not have learned the 'what-it-is-like-tobe-a-person-with-Alzheimer's-disease prior to actually living through it. This satisfies the epistemic condition of the TE. Similarly, Mr Smart's core preferences have shifted drastically, notably away from philosophy. ${ }^{18}$ This satisfies the personal condition of the TE. ${ }^{19}$ As such, and similar to the vampire case by Paul, Mr Smart's projections about what he would prefer done in the case will be unreliable, and therefore should not play any sort of a binding role in a care decision.

For me, it is not that Mr Smart was in some way "irrational" in creating his advance directive, or that the wishes described within it were not thoroughly analyzed before a decision was made. Philosophers tend to over-analyze anything we get our hands on, so this cannot be what is going on here. Rather, the information used in the analysis was simply the wrong information, since the information necessary was inaccessible to Mr Smart before he was actually within (or on the other side of) the TE. Without knowing what it is like to be a person with Alzheimer's (and the accompanying dementia), Mr Smart was doing something more akin to guessing when analyzing the condition from the outside. ${ }^{20}$ Paul, in talking about becoming a parent, says, "The idea isn't that you don't know what it's like to babysit, change diapers, or be very tired before you become a parent. Rather, what you don't know is its most important and distinctive feature: what it will be like to form and occupy (my emphasis) the identity-constructing, preference-changing, physically and emotionally overwhelming perspective of being a parent" (Paul, 2015b). Similarly, it is not that Mr Smart didn't know (or couldn't find out) what it's like to be confined to a facility, or be cared for by healthcare professionals around the clock, or other similar aspects of latestage Alzheimer's. Rather, it is that Mr Smart simply could not know what it is like to occupy the role of a person with late-stage Alzheimer's.

Of course, with many other kinds of TE's, a person can merely revise their earlier assessment of what it would be like to be on the other side of a TE. For example, suppose an avid marathon runner were to think, "I would rather die than live without being able to run marathons." Then, suppose that through some accident they actually did lose the ability to run marathons, perhaps by becoming a paraplegic. Normally, the person would find other things valuable in their life post-accident, and would revise their earlier belief that they would rather die than not be able to run marathons. The interesting part about the Alzheimer's case is that the loss of competency that accompanies the disease ensures that a patient like Mr Smart cannot revise earlier stated or documented preferences to reflect their new state of being. Hence, the problem with a case like Mr Smart is that decisions made prior to the TE will often have life-or-death implications. This is why I argue that such decisions should not be binding.

One caveat to the above argument is that there needs to be a genuine conflict of interests between the advance directive and the patient's contemporary interests. If this does not exist, then there does not seem to be a problem with honoring the directive. This argument only targets circumstances when there is a frustration of the incompetent patient's contemporary interests.

One objection to this is that Mr Smart indeed could have predicted that he would become a pleasantly demented person (or at least taken this into account), and as such his decision to not receive life-saving treatment via the directive would be binding (even if regrettable) in the present case. I agree that Mr Smart could have taken such a fact under consideration, but I think this kind of objection does not threaten my conclusion. Suppose that $\mathrm{Mr}$ Smart actually knew that he would become pleasantly demented. What he still could ${ }^{\star} \operatorname{not}^{\star}$ know is the subjective value of being pleasantly demented. In other words, in weighing his current subjective preference towards philosophy with his possible future subjective preference, he comes out in favor of the philosophy. However, this is precisely the problem with these kinds of future projections, because Mr Smart does not know how much value to place on being pleasantly demented, while he does know how valuable he finds philosophy.

Tom Dougherty, Sophie Horowitz, and Paulina Sliwa would object to the kind of response just given, saying that while $\mathrm{Mr}$ Smart might not know the phenomenal character of living as a pleasantly demented person, he could still rationally estimate the intrinsic value of living as a pleasantly demented person (Dougherty et al., 2015). He could simply observe the behavior of an already-pleasantly-demented person, call her Mrs Y, and know that the experience of being pleasantly demented is intrinsically valuable for her. ${ }^{21} \mathrm{He}$ sees Mrs Y beaming while taking a walk in the sunshine, or experiencing what appears to be sincere happiness while she eats her various meals throughout the day. Thus, having an estimate of the value of being pleasantly demented by observing Mrs Y places Mr Smart in no unusual position when he is creating his advance directive. ${ }^{22}$

Paul replies to this argument by claiming that mere intrinsic value is not what she is worried about, unless one is conflating intrinsic value with subjective value. For Paul (2015b), subjective value "ontologically depends on the nature of the lived experience that constitutes it". This differs importantly from intrinsic value, which the trio define as "value that is had by an outcome in virtue of its intrinsic properties," because such value has nothing to do 
with the vital role the "lived experience" plays in subjective value (Paul, 2015b). This is important to defend my claim, because it is the "lived experience" of Alzheimer's that I argue cannot be discerned in creating an advance directive. Therefore, this challenges the notion that the patient has adequately assessed a potential future which includes the possibility of being "pleasantly demented", even if they accurately predict that they will be in that circumstance.

Another challenge to this way of viewing the conflict between an advance directive and a patient's current interests is by appealing to precedent autonomy. I take precedent autonomy to be the idea that decisions made autonomously by a person will extend to a time when that person is no longer autonomous (that is, incompetent). For example, Mr Smart formed his directive while in full use of his mental powers, and he endorsed the decisions made in the directive. Thus, he made the directive autonomously. ${ }^{23}$ After becoming severely demented by the progression of his Alzheimer's disease, Mr Smart's previously made autonomous decisions will take precedence over his current interests, since he can no longer make autonomous decisions. As David DeGrazia notes, "Since the severely demented individual is presently incapable of autonomy, this reasoning vindicates a strong presumption in favor of honoring advance directives..." (Degrazia, 2005). ${ }^{24}$

Of course, Degrazia is reinforcing the original argument made by Ronald Dworkin, which invokes the distinction of critical and experiential interests mentioned earlier (Dworkin, 1993). So, another way to frame the objection is to say that a patient's critical interests are served by making the directive binding. The only possible conflict with these critical interests are the mere experiential interests of the currently demented patient (who cannot generate or recognize critical interests any longer). Seana Shiffrin argues with this conclusion, claiming that the experiential interests of the dementia patient amount to significant interests that can generate genuine conflict with critical interests. She says, "the arguments I have given show that the contemporary interests as well as the will of demented people may clash with that person's exercise of precedent autonomy as well as the critical interests the person had before she became demented and that the contemporary interests and decisions should drive our deliberations as to how to treat the demented" (Shiffrin, 2004). ${ }^{25}$

Another objection along the same lines is made by John $\mathrm{K}$. Davis. He uses the following argument:

(1) When a person has conflicting preferences on an issue, and a third, resolution preference favoring one conflicting preference over the other, respect for autonomy requires respecting the resolution preference.

(2) In cases where the person's competence declines over time, sometimes the resolution preference is a former preference, existing at the same time as the conflicting former preference.

(3) It is possible to respect a person's autonomy by respecting his or her former preferences.

(4) Therefore, when there is a former resolution preference favoring an earlier conflicting preference over a later conflicting preference, respecting autonomy requires respecting the former resolution preference and the conflicting former preference it favors (Davis, 2009).

This argument is meant to show that a patient can resolve conflicts between present and future conflicting preferences by creating a "resolution preference", which is the preference that the agent desires to be fulfilled above the conflicting preference. Hence, respecting resolution preferences contained in an advance directive, which have taken into account future preferences, will best respect the patient's autonomy. The reason that disregarding the patient's current preference is not a violation of autonomy is because the patient who is incompetent is unaware of the conflicting former preference, and thus cannot form a tacit resolution preference in favor of their own contemporary interest. ${ }^{26}$ However, I disagree with this line of argument. By saying that disrespecting the current interest of the incompetent patient will not amount to a violation of autonomy unless they are aware of the conflict begs the question as to how there is a conflict of preferences in the first place. What I mean is, smuggling an awareness requirement for preferences to mean anything into a case with incompetent patients is rigging the game, so to speak. In addition to this, even if the argument were to go through, it would seem to prove too much. This argument would give carte blanche authority to advance directives, even if they contain questionable content on other grounds. Either way, I think my argument can survive the objection.

\section{Conclusion}

In summary, my argument claims that advance directives should not be considered morally binding when they are in direct conflict with the contemporary interests of an incompetent patient. I focus on the case of a patient suffering from Alzheimer's disease because I believe the disease can be characterized as a transformative experience. If this is true, then an advance directive will not be able to take into account any subjective values that occur within or beyond the transformative experience, and thus will reduce the moral authority of an advance directive that relies on them. Since an advance directive will often rely on these kinds of subjective value projections, this conclusion will directly affect the way we view the binding nature of such directives in cases involving transformative experiences. This is importantly different from similar conclusions made prior to this paper, because others have merely argued that the conflicting interests of the currently demented patient are worth protecting, or that interests that a patient no longer has should not be considered interests any longer. My argument does neither. Instead, my argument can accept both sides of the argument (that any interests a patient no longer has are still interests, and that the current interests of the demented patient are worth protecting) and still conclude that the advance directive will not necessarily be morally binding. I do this by emphasizing that an agent cannot have access to the relevant knowledge to weigh any conflicts between current interests and future interests (of the relevant kind, the "lived experience" kind). I do not argue that advance directives have no place or function, since when there is not a conflict of preferences or interests (or other so-called "trumping" factors in certain cases), the directives should be honored. I might tentatively suggest that advance directives be used more as a tool in the broader picture of the care of patients with declining competence rather than the de facto authority that they are viewed as in much of the literature.

\section{Notes}

1 And, as Dresser notes in that paper, one can argue using Derek Parfit's Complex View of personal identity that the later incompetent patient is actually a different person because of the lack of psychological continuity. I will speak more on this topic shortly.

2 Unfortunately, there are numerous other papers and chapters that could be appealed to for interesting arguments surrounding this debate, but in the interest of brevity I have attempted to present the arguments most relevant to my own line of argumentation.

3 Both definitions have been adapted from a lecture given by L.A. Paul at a Colloquium series put on at Florida State University in the Spring of 2015. Similar definitions are found in the second chapter of Paul's book (Paul, 2014).

4 To be sure, all kinds of experiences could fall into this category if we were to make experiences so fine-grained that every kind of experience becomes ET. However, as 
Paul (2014) mentions, "It is more natural, especially in a decision-theoretic context, to partition new experiences in a coarse-grained way, perhaps into experiential kinds". In this way, the discussion can remain focused on the particularly interesting cases of ET, rather than being bogged down with the more mundane and uninteresting cases.

5 Of course, this list is not exhaustive, and many in this list are also listed in Paul's work. Paul also notes that there are many experiences that classify as transformative, but are uninteresting. For example, if I order a cheeseburger from my favorite diner, then I will have a transformative experience concerning that cheeseburger, since I have not experienced eating that ${ }^{*}$ particular ${ }^{*}$ cheeseburger (considering the exact temperature to which it has been cooked, the exact ratios of lean to fat in the meat, and the precise blend of seasonings that are in it, not to mention the ripeness of the toppings, etc.). However, these cases are not high-stakes, and thus do not concern us in the same ways as choosing between life and death under various circumstances.

6 Though, it might be possible to have some idea of the changes to come, experiencing them will almost surely prove that your conceptions were mostly (if not all) false.

7 Obviously, such a decision is not possible (since there are no vampires, at least the way pop-culture defines them), however the vampire case serves to highlight the relevant features of Paul's theory.

8 When I say "of the relevant sort" in the parenthetical, what I mean is that Paul targets normative decision-theoretic models in her argument. Whether she succeeds in that argument lies outside of the scope of this paper.

9 Again, for her argument, this is on a normative decision-theoretic model.

10 One problem this is related to is the fundamental identification problem. Roughly, an agent will have difficulty in choosing which agent who has made such a decision before will be relevantly similar to herself to provide adequate testimonial knowledge. As Paul says, "Individuals are complex entities, [and] each person has a distinctive psychological profile and background, and so may respond to an event in a unique way" (Paul, 2014).

11 I follow Beauchamp and Childress' general view of what informed consent amounts to, as well as the requirements of autonomy (Beauchamp and Childress, 2009).

12 By rational here, I am referring to a kind of practical reasoning. When one is deciding what to do, one looks at relevant possible outcomes for each potential action and decides accordingly. However, in the case above (which will be discussed in more detail in the next section) a patient cannot know the relevant possible outcomes, and so practical reasoning in this sense (rationality) fails.

13 This thesis will avoid dealing with the charges of irrationality that are involved in the stronger thesis, while still challenging the authority of advance directives as such.

14 This version of the scale I have adapted from the original scale put forth by Barry Reisberg (Reisberg et al., 1988).

15 Several cases of Alzheimer's appear in Dworkin's Life's Dominion, and in particular the Margo case is relevantly similar to my own (Dworkin, 1993).

16 Granted, these are seemingly rather vague instructions, but in truth this is the case with most Advance Directives, since one cannot accurately predict "exactly" what kind of illness or condition will occur in the future, and as such they invariably suffer from a vagueness problem that causes them, in many cases, to lose applicability.

17 Though this case is familiar to those who have read the literature, I hope that by giving more detail and coupling it with the Reisberg scale I can give a more finegrained approach to talking about a complex issue.

18 Though I did not specify in the case what his preferences were once Mr. Smart became a pleasantly demented person, one can easily imagine that he could nonverbally express his preferences for things like peanut butter and jelly sandwiches, or conversations with care givers or other patients. Most notably, these could be (though not by necessity) things that he had no preference for before his disease.

19 I use the terms "epistemic condition" and "personal condition" to reference the ET and PT nature of a TE.

20 What's more, even an expert on Alzheimer's would be in a similar position to Mr. Smart.

21 In their argument, they also offer two other methods to obtain this intrinsic value, testimony and similar experience. However, I felt that these would be more difficult in the particular case of Alzheimer's, so I chose to emphasize their method of observation for the objection.

22 This would be assuming that he thought it possible he would be diagnosed with Alzheimer's, and that he could possibly be pleasantly demented, which are not going to be in every case. Another objection to advance directives in general.

23 This would at least seem to meet the criteria for autonomous decision making found in Tom Beauchamp and David Childress' "Principles of Biomedical Ethics" (Beauchamp and Childress, 2009). I will not dispute their notion of autonomy here, though I think there may be some interesting ground to challenge it in the case at hand.

24 Note here that Degrazia is talking about dementia broadly speaking, whereas I am focused on the case of Alzheimer's disease, which is a cause of dementia. Nonetheless, my arguments should apply more generally to cases of dementia that do not arise due to Alzheimer's.
25 I am in agreement with Shiffrin's argument, so feel the need to say no more here. 26 Steven Sabat has an interesting piece where he argues that many Alzheimer's patients in fact ${ }^{*} \mathrm{do}^{*}$ still have some level of awareness of former interests and preferences, depending on the progression of the disease (Widdershoven, 2011). This may have some interesting ramifications as well for Davis' argument, since a patient may indeed recognize a former interest and possibly form a tacit resolution preference if it conflicts with a current preference.

\section{References}

Beauchamp T and Childress J (2009) Principles of Biomedical Ethics, 7th ed., Oxford University Press: New York.

Davis J (2009) Precedent Autonomy, Advance Directives, and End-of-Life Care Oxford Handbooks Online.

Degrazia D (2005) Human Identity and Bioethics. Cambridge Press: Cambridge, US.

Dougherty T, Horowitz S and Sliwa P (2015) Expecting the unexpected. Res Philosophica; 92 (2): 301-321.

Dresser R (1986) Life, death, and incompetent patients: Conceptual infirmities and hidden values in the law. Arizona Law Review; 28 (3): 373-406.

Dworkin R (1993) Life's Dominion, 1st ed., Harper Collins Publishers: London.

Hanson S, Doukas D (2009) Advance directives. In: Ravitsky V, Fiester A and Caplan A (eds). The Penn Center Guide to Bioethics. Springer Pub: New York 750-759.

Jaworska A (2009) Advance Directives and Substitute Decision-Making. [online] Stanford Encyclopedia of Philosophy, https://plato.stanford.edu/archives/ sum2009/entries/advance-directives, accessed 26 September 2016.

Paul L (2014) Transformative Experience. Oxford Press: Oxford.

Paul L (2015a) What you can't expect when you're expecting. Res Philosophica; 92 (2): 149-170.

Paul L (2015b) Transformative choice: Discussion and replies. Res Philosophica; 92 (2): 473-545.

Reisberg B, Ferris SH, de Leon MJ and Crook T (1988) Global deterioration scale (GDS). PsychoPharmacology Bulletin; 198824 (4): 661-663.

Shiffrin S (2004) Autonomy, beneficence, and the permanently demented. In Burley J and Dworkin R (eds). Dworkin and His Critics. Blackwell Publishing: Malden, MA.

Trachsel M, Hermann H and Biller-Andorno N (2015) Cognitive fluctuations as a challenge for the assessment of decision-making capacity in patients with dementia. American Journal of Alzheimer's Disease \& Other Dementias; 30 (4): 360-363.

Widdershoven G (2011) Empirical Ethics in Psychiatry, 1st ed., Oxford University Press: Oxford, pp 123-140.

\section{Data availability}

Data sharing not applicable to this article as datasets were neither generated nor analysed.

\section{Additional information}

Competing interests: The author declares that there are no competing interests.

Reprints and permission information is available at http://www.palgrave-journals.com/ pal/authors/rights_and_permissions.html

How to cite this article: Boerstler K (2017) The challenge of transformative experiences for advance directives: predicting a future with Alzheimer's disease. Palgrave Communications. 3:17034 doi: 10.1057/palcomms.2017.34.

Publisher's note: Springer Nature remains neutral with regard to jurisdictional claims in published maps and institutional affiliations.

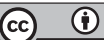

This work is licensed under a Creative Commons Attribution 4.0 International License. The images or other third party material in this article are included in the article's Creative Commons license, unless indicated otherwise in the credit line; if the material is not included under the Creative Commons license, users will need to obtain permission from the license holder to reproduce the material. To view a copy of this license, visit http://creativecommons.org/licenses/by/4.0/

(C) The Author(s) 2017 